\title{
Association of NFkB1 Gene Polymorphism with Inflammatory Markers in Patients of Type 2 Diabetes Mellitus with or without Renal Involvement in Eastern India
}

\author{
Sonalika Behera1 ${ }^{1}$, Andrew Abel Lamare², Roma Rattan², Bijan Patnaik ${ }^{1}$, Sidhartha Das ${ }^{1}$ \\ ${ }^{1}$ Department of Medicine, Sriram Chandra Bhanja Medical College, Cuttack, Odisha, India \\ ${ }^{2}$ Department of Biochemistry, Laboratory of Molecular Science, Sriram Chandra Bhanja Medical College, Cuttack, Odisha, India \\ Email: drsonalika10@gmail.com
}

How to cite this paper: Behera, S., Lamare, A.A., Rattan, R., Patnaik, B. and Das, S. (2020) Association of NFkB1 Gene Polymorphism with Inflammatory Markers in Patients of Type 2 Diabetes Mellitus with or without Renal Involvement in Eastern India. Journal of Diabetes Mellitus, 10, 169-181. https://doi.org/10.4236/jdm.2020.103014

Received: July 3, 2020

Accepted: August 9, 2020

Published: August 12, 2020

Copyright $\odot 2020$ by author(s) and Scientific Research Publishing Inc. This work is licensed under the Creative Commons Attribution-NonCommercial International License (CC BY-NC 4.0). http://creativecommons.org/licenses/by-nc/4.0/

\begin{abstract}
Aims: To evaluate the association of Nuclear factor kappa B1(NFkB1) gene polymorphism with inflammatory markers Urinary Monocyte Chemoattractant Protein 1 (UMCP1) and Tumor Necrosis Factor alfa (TNF alfa) in Patients of diabetes mellitus with or without renal involvement in Eastern India. Material and Methods: Consecutive Patients of Type 2 Diabetes Mellitus (DM) with or without microalbuminuria attending SCB MEDICAL COLLEGE and HOSPITAL Medical OPDs in between September 2018 to September 2019 were recruited in this study. Patients were subjected to blood and urine investigations. DNA extraction and Restriction fragment Length Polymorphism (RFLP) was done in Department of Biochemistry. Controls were unrelated healthy attendants with no history of Diabetes Mellitus, HTN, Chronic Kidney Disease (CKD). Results: Mean Systolic BP, Fasting Blood Glucose, Post Prandial Blood Glucose, HBA1c, Total Cholesterol were significantly higher in diabetes mellitus and diabetic nephropathy groups than control group. Estimated Glomerular Filtration Rate was significantly lower in diabetic nephropathy ( $\mathrm{p}$ value $<0.001$ ). UMCP1, Urinary Albumin Creatinine Ratio, TNF alfa were higher in diabetes mellitus and nephropathy with $\mathrm{p}$ value $(<0.001,0.006<0.001)$ respectively. In between DM and Diabetic Nephropathy groups nfkb1 gene expression, umcp 1 and tnf alfa levels were significantly increased in Diabetic nephropathy with p value $0.019,<0.01,0.001$ respectively. Insertion/insertion NFkB1 gene polymorphisms were more in diabetic nephropathy group and were positively correlated with inflammatory markers UMCP1 $(r=0.517, \mathrm{p}<0.01)$ and TNF alfa $(\mathrm{r}=0.172, \mathrm{p}=0.19)$. Conclusion: insertion/insertion NFkB1 gene polymorphism increases the risk of nephro-
\end{abstract}


pathy by 2.52 times $(\mathrm{OR}=2.52,95 \% \mathrm{CI}: 0.04-0.63$, p value $=0.019)$ in diabetes patients in eastern India.

\section{Keywords}

DN: Diabetic Nephropathy, UACR: Urinary Albumin Creatinine Ratio, UMCP1: Urinary Monocyte Chemoattractant Protein 1, TNF Alfa: Tumor Necrosis Factor Alfa, NFkB1: Nuclear Factor Kappa B, Ins/Ins Polymorphism: Insertion/Insertion Polymorphism, Del/Del Polymorphism: Deletion/Deletion Polymorphism, Ins/Del Polymorphism: Insertion/Deletion Polymorphism

\section{Introduction}

India is home to 72.9 million people with diabetes and 24 millions with impaired glucose tolerance is expected to become the country with largest population of people with diabetes by 2045 , as per the $8^{\text {th }}$ edition of International Diabetes Federation(IDF) Diabetes Atlas, 2017 [1]. The complications of Diabetes Mellitus $(\mathrm{DM})$ are due to the biochemical and structural changes in basement membrane proteins in different organ systems. Chronic hyperglycemia causes non-enzymatic glycosylation of proteins such as collagen and elastin, etc. leading to thickening of basement membrane and microangiopathy [2]. A previous study In SCB MCH, 2016 nephropathy was found in 56\% of cases of type 2DM (Soumya et al.) [3]. Previous studies have reported prevalence of nephropathy in India as: 41\% [4], $30.2 \%$ [5], 25.5\% [6], 36.3\% [7], and 23.0\% [8], respectively. The WHO multicentric study of vascular disease in diabetics, reported a wide geographical variation in prevalence of diabetic nephropathy. It ranged from 2.4\% (Hong Kong), 23\% (Delhi), to 37\% (Oklahoma, USA) respectively, [9] showing variations due to different ethnicity, geography and sample size. A study from Cuttack has revealed Diabetic Nephropathy (DN) as the cause of death in $17 \%$ and $35 \%$ of cases in T2DM patients in 1977 and 1988 respectively [10]. Pioneering epidemiological work done by Indian CKD Registry established under the aegis of Indian Society of Nephrology (ISN) had made pertinent observations that diabetes mellitus is the cause of CKD in $31.2 \%$ of patients [11]. Microalbuminuria in Type-2DM patients found to be a marker of generalised vascular endothelial dysfunction in the same study [12]. The Chennai Urban Rural Epidemiological Study (CURE) revealed overt proteinuria in $2.2 \%$ and microalbuminuria in $26.9 \%$ of population [13]. It has been reported that among 4837 patients with chronic renal failure seen over a period of 10 years, the prevalence of diabetic nephropathy was $30.3 \%$ in India [14]. A study conducted in Cuttack 2017 showed histopathologically, DGS was the most predominant form of renal abnormality found in $93.75 \%$ followed by NGS in $62.50 \%$, membranous nephropathy in $12.5 \%$ and focal necrotising glomerulonephritis in $6.25 \%$ of cases respectively (S. Nayak et al.) [15]. Microinflammation is a major cause for development and progression of DN. Inflammatory cascade includes activation of transcription factors, cytokine, growth factor. 
NFkB is a transcription factor that has very important role in the regulation of many genes encoding mediators of inflammation, cell cycle, cell apoptosis, viral replication, variety of auto immune diseases [16]. NF- $K b$ family consists of five members in mammals: NF- $\kappa$ B1: p105/p50, NF- $\kappa$ B2: p52/p100, RelA: p65, RelB, and c-Rel. The chief form of NF- $\kappa$ B is a hetero-dimer of the p50 and p65/RelA subunits, encoded by the NFKB1 and RelA gene. Normally, inactive NF- $\kappa$ B is present in the cytoplasm bound to Inhibitors of $\mathrm{kB}$ (IkBs). The Cells when exposed to a variety of proinflammatory stimuli leads to the quick phosphorylation followed by ubiquitinylation, and finally proteolytic breakdown of I- $K \mathrm{~b}$ [17]. This leads to transfer of NF- $k$ B in nucleus and causing increased transcription of gene. NF- $\kappa \mathrm{B}$ transcriptionally regulates many downstream proinflammatory genes, mainly including monocyte chemoattractant protein-1 $(M C P-1)$, tumor necrosis factor-alpha (TNF- $\alpha$ ) [18]. TNF alfa, MCP-1, IL-1 IL-6 are produced, expressed and released by infiltrating inflammatory cells and also by different cells of kidney such as endothelial, mesangial, glomerular, tubular epithelial cells Current knowledge reveals that functional $N F K B 1$ promoter SNP consisting of a insertion/deletion (-94 ins/del ATTG) (rs28362491) as regulatory effect on the NFKB1 gene [19]. Das et al. 2012 in Cuttack studied Diabetes mellitus with macrovasular studies had significantly higher serum hsCRP and NF-kB expression and significantly lower levels of adiponectin than group C ( $\mathrm{p}=0.0001,0.007$, and 0.02 , respectively) [20]. Gautam A. [21] et al. enrolled 300 patients with Type 2 diabetes mellitus including Diabetes pts with or without microalbuminuria, healthy controls to assess the impact of type 2 diabetes mellitus on glomerular capillary permeability, measured using TNF alfa, MCP-1, NFKB1 gene polymorphism, the presence of microalbuminuria. This study demonstrated statistically significant increase in glomerular damage in patients with Type 2 DM compared with healthy controls. P. Tilak et al. compared Umcp-1 [22] in 64 type 2 DM pts and 12 healthy controls. They found that patients with DM have higher Umcp-1 in comparison with controls. This increase was significantly related to the duration of DM and the presence of microalbuminuria. Till date there are very very few studies regarding NFkB gene polymorphism and levels of UMCP1 and TNF alfa in diabetes mellitus patients and diabetic Nephropathy. Hence the present study was the first ever study conducted to see the association of NFkB1 gene polymorphism and its correlation with inflammatory markers like umcp1 and TNFalfa in patients of Type-2 Diabetes Mellitus with or without Nephropathy in eastern India.

\section{Study}

It is a case control study in a tertiary centre.

\subsection{Ethical Clearance}

This study has been approved by Institutional Ethics Committee, S.C.B. Medical College, Cuttack-753007 with Ethics Committee Regd. No. ECR/84/Inst/OR/2013. 


\subsection{Materials}

Consecutive Patients of Type 2 Diabetes Mellitus (DM) with or without microalbuminuria attending SCB MEDICAL COLLEGE and HOSPITAL Medical OPDs in between September 2018 to September 2019 were recruited in this study. Patients were subjected to blood and urine investigations.DNA extraction and Restriction fragment Length Polymorphism (RFLP) was done in Molecular diagnostic lab, Department of Biochemistry. Group 1 Controls were unrelated healthy attendants with no history of Diabetes Mellitus, HTN, Chronic Kidney Disease (CKD). Group 2 Type 2 Diabetes Mellitus without microalbuminuria as indicated by $<30 \mathrm{mg}$ of albumin per gram of creatinine on spot urine sample and in the three most recent lab reports. Type $2 \mathrm{DM}$ was diagnosed according to WHO guidelines [1]. Group 3 Diabetic nephropathy patients were defined as on the basis of Kidney Disease Improving Global Outcome (KDIGO) classification of chronic kidney disease [23] and GFR calculated using Cockrauft's Formulae. Cockrauft's and Gault formulae: Creatinine Clearance $=\{((140-$ age $) \times$ weight $) /$ $(72 \times \mathrm{SCr})\} \times 0.85$ (if female) [24]. All the subjects had age (25 - $60 \mathrm{yrs)}$.

Exclusion Criteria: 1) Gestational Diabetes Mellitus. 2) Subjects having macrovascular complication of diabetes like CAD, stroke were not included. 3) Hyperglycemia due to endocrine disorders. 4) Kidney disease (hypertensive nephropathy, chronic glomerular nephritis, tubule interstitial disease, obstructive uropathy, CCF, malignancy, liver disorders). 5) Presence of autoimmune disorders. 6) Infections. 7) The subjects who did not able to understand and sign the study specific informed consent were excluded from study. 8) History of diabetic ketoacidosis or hypoglycemic coma in the past 3 months preceding the study. 9) Subjects on Renin-angiotensin-aldosterone system inhibitors, statins, aspirin or using immunomodulatory medications (vit $\mathrm{d}$ analogues) were also excluded from the study. All the subjects gave the written informed consent prior the study began.

\subsection{Methodology}

Antropometric details such as height, weight, BMI and detailed clinical examinations were done. Fasting venous blood and after two hour post prandial blood collected and were kept in clot activator vials for serum biochemical analysis, in EDTA vials for molecular techniques and in oxo-fluoride vials for plasma glucose. Plasma glucose levels were estimated by GOD-POD (Glucose oxidase peroxidase) method adapted to autoanalyzer (Toshiba 120FR, JAPAN). Serum total cholesterol is estimated by CHOD-PAP (cholesterol oxidase-peroxidase) method adapted to autoanalyzer (Toshiba 120FR, AGGAPE, Japan). Estimation of Serum Triglyceride by Glycerol-3-Phosphate-oxidase/Peroxidase method (GPO-TOPS) adapted to autoanalyzer (Toshiba 120FR.AGGAPE, JAPAN). Estimation of serum hdl cholesterol by selective inhibition method adapted to autoanalyzer (Toshiba 120FR, JAPAN). Serum LDL level was estimated by Friedewald formula. 
FRIEDEWALD FORMULA, LDL $=$ Total Cholesterol $-[$ HDL $+($ Triglyceride/5)] Results were expressed in mg/dL. Serum VLDL level was estimated by Friedewald formula. FRIEDEWALD FORMULA, VLDL $=$ Triglyceride/5. Results were expressed in $\mathrm{mg} / \mathrm{dl}$. Serum urea level was estimated by (GLDH/KINETIC) method adapted to autoanalyzer (Toshiba 120FR, JAPAN). Serum creatinine was estimated by enzymatic method adapted to autoanalyzer (Toshiba 120FR). Glycated haemoglobin were done by High-performance liquid chromatography. First-morning urine samples were collected under sterile conditions. $10 \mathrm{ml}$ of urine were centrifuged at $1500 \mathrm{rpm}$ for $10 \mathrm{~min}$ at 4 degree centigrade and the supernatant was stored at $-80^{\circ} \mathrm{C}$ until UMCP-1 assay. The same specimen was used for urinary the measurement of albumin-creatinine ratio, ACR $(\mu \mathrm{g} / \mathrm{mg})$. $\mathrm{ACR}<30 \mu \mathrm{g} / \mathrm{mg}$ was defined as normoalbuminuria, $30-300 \mu \mathrm{g} / \mathrm{mg}$ as microalbuminuria, and ACR $>300 \mu \mathrm{g} / \mathrm{mg}$ as macroalbuminuria [23]. Urine microalbumin were done in standard kits adapted to semi auto analyser (Toshiba $120 \mathrm{FR}$, AGAPPE). Urine Albumin: Creatinine Ratio (UACR) calculated by the formula, which has been approved by National Kidney Disease Education Program. UACR in $\mathrm{mg} / \mathrm{g}=$ Urine albumin $(\mathrm{mg} / \mathrm{dL}) /$ Urine creatinine $(\mathrm{g} / \mathrm{dL})$. Serum samples were separated from clotted blood by immediate centrifugation (1500 rpm for $10 \mathrm{~min}$ ), aliquoted, and stored at $-80^{\circ} \mathrm{C}$ until TNF- $\alpha$ assay. UMCP1, S.TNF alfa by ELISA done in standard kits adapted to Lisa scan (Evolis twin plus, Biorad).

DNA extraction and polymorphism genotyping: Blood samples of $2 \mathrm{ml}$ were collected in blood collection tubes with EDTA. Genomic DNA was extracted using a DNA isolation kit according to manufacturer's protocol (Genomic DNA isolation Kit, Genxbio). To determine polymorphism, regions of 285 bp in NF- $\kappa$ B1 were amplified using the following primer sets (Forward 5'-TGGGCA CAAGTCGTTTATGA-3' and Reverse 5'CTGGAGCCGGTAGGGAAG-3') [25]. PCR was performed by amplifying $20 \mathrm{ng}$ of DNA in a $50 \mu \mathrm{l}$ reaction, 19 PCR buffer, $2 \mathrm{mM} \mathrm{MgCl} 2$ (NF- $\kappa \mathrm{B} 1$ ), $0.5 \mathrm{mM}$ dNTPs, $0.5 \mu \mathrm{M}$ each primer, and $0.5 \mathrm{U}$ Taq DNA polymerase. The amplification conditions were $1 \mathrm{~min}$ at $95^{\circ} \mathrm{C}, 30 \mathrm{~s}$ at $95^{\circ} \mathrm{C}, 30 \mathrm{~s}$ annealing at $60^{\circ} \mathrm{C}, 1 \mathrm{~min}$ at $72^{\circ} \mathrm{C}$, and finally $5 \mathrm{~min}$ at $72^{\circ} \mathrm{C}$, for 35 cycles. (VERITI 96 WELL THERMAL CYCLER, THERMOFISHER SCIENTIFIC, APPLIED BIOSYSTEMS, USA).

For detection of the -94 ins/del ATTG polymorphism in NF- $\kappa$ B1, a PCR product of 281/285 bp was digested with restriction enzyme PfIMI (10 U/ $\mu$, Fermentas), which has a recognition site in this region. Five microliters of PCR product was digested by PfIMI in a $25 \mu \mathrm{l}$ reaction $(2.5 \mu \mathrm{l} 109$ buffer, $0.3 \mu \mathrm{l}$ PfIMI) at $37^{\circ} \mathrm{C}$ overnight. There are two ATTG repeats at its promoter region, one allele of which has an ATTG insertion (ins). Therefore, one unique recognition site takes the form 5'...CCANNNN NTGG...3' at the ins allele. Consequently, the ins allele was cleaved into two fragments of $45 \mathrm{bp}$ and $240 \mathrm{bp}$ after restriction digestion. However, there was no cleavage at the deletion allele (del) that has only one ATTG at its promoter [25]. The bands of digested products were visualized in $2 \%$ agarose gel electrophoresis stained with ethidium bromide. 


\subsection{Statistical Analysis}

Statistical analysis was done using SPSS package version 20.0 (SPSS Inc., Chicago, IL, USA). Quantitaive variables were described as mean \pm standard deviation unless otherwise indicated. Qualitative variables were described by percentage. Pearson's correlation co efficient, ANOVA with post Hoc analysis, logistic regression analysis, multivariate analysis were used. For all statistical tests $\mathrm{p}$ value $<0.05$ was considered significant.

\section{Results}

150 numbers of consecutive subjects recruited for study in between sepember 2018 to September 2019 were divided in to three groups and 23:27 (M:F) in control, 21:29 (M:F) in type 2 diabetes mellitus without microalbuminuria and 23:27 (M:F) in diabetes nephropathy groups. Age and BMI were similar in three groups without any statistical significance. Significant Hypertension in diabetic nephropathy group with $\mathrm{p}$ value 0.002 . FBG, PPBG, HBA1C, Total CHOL. were significantly higher in diabetes mellitus and diabetic nephropathy groups than control group. GFR was significantly lower in diabetic nephropathy ( $\mathrm{p}$ value < 0.001) UMCP1, UACR, TNF alfa is higher in diabetes mellitus and nephropathy with $p$ value $(<0.001,0.006 .<0.001)$ respectively. In between DM and DN nfkb1 gene expression, umcp1 and tnf alfa levels were significantly increased in Diabetic nephropathy with $\mathrm{p}$ value $0.019,<0.01,0.001$ respectively. In control group ins/ins nfkb1 gene genotype frequencies were $12(24 \%)$ and deletion/deletion polymorphisms are $38(76 \%)$. No insertion/deletion polymorphism in control group. In Diabetes mellitus group ins/ins nfkb1 gene polymorphisms are 24 (48\%), deletion/deletion polymorphisms were 19 (38\%) and insertion/deletion polymorphisms were 7 (14\%). In Diabetes nephropathy group ins/ins nfkb1 gene polymorphisms were 35 (70\%), deletion/deletion polymorphisms were 14 (28\%) and ins/del polymorphisms were $1(2 \%)$. Ins/ins polymorphisms was positively co related with umcp $1(\mathrm{r}=0.517$, p value $<0.01)$. del/del polymorphism positively corelated with tnf alfa $(r=0.137$, $\mathrm{p}$ value 0.01$)$. Ins/del polymorphisms was positively co related with umcp1 with $(r=0.323$, $p$ value $<0.012)$. ins/ins nfkb1 gene polymorphism increases the risk of diabetic nephropathy by 2.52 times in diabetes patients $(\mathrm{OR}=2.52,95 \%$ CI: $0.04-0.63$, $\mathrm{p}$ value $=0.019)$.

\section{Discussion}

The present study is a hospital based retrospective study. The transcription factor NFKB1 regulates expression of many genes related to immune function, growth function, cell proliferation, apoptosis [18].

In control group out of 50 persons 23 are males and 27 are females. In diabetic without nephropathy group 21 are males and 29 are females. In diabetic nephropathy groups 23 are males and 27 are females. No statistical significance in sex between groups. 
Table 1 shows anthropometric and biochemical parameters values are in mean \pm standard deviation. Statistical significance was considered $\mathrm{p}$ value $<0.05$. Age and BMI was similar among the study subjects in all the groups. No statistical difference between study and control groups. Percentage of subjects with hypertension was significantly higher in microalbuminuric and macroalbuminuric groups compared to the normoalbuminuric group. $\mathrm{BMI}=, \mathrm{SBP}=$ systolic blood pressure, $\mathrm{DBP}=$ diastolic blood pressure. Mean $\mathrm{BP}$ among all three groups mentioned. Mean BP in diabetic nephropathy are higher than in control and diabetes patients. This study holds true with Ziyadh et al. [26] with $\mathrm{p}$ value < 0.05. FBG, PPBG, HBA1C were significantly higher in diabetes mellitus and diabetic nephropathy groups than control group. Lipid profile among all three groups mentioned. Total Cholesterol, TG are higher in diabetes group than control. These findings are consistent with M. F. Laker. Total Cholesterol is higher in diabetic nephropathy group ( $\mathrm{p}$ value $=0.03$ ). TG, LDL, HDL, VLDL are not significantly different in between groups. Palazhy S. et al. [27] showed total cholesterol, LDL, TG are significantly higher in diabetic nephropathy group. Viverti. G. et al. [28] shows similar results with our study. But we contradict a Japanese study which has shown LDL levels are lower in nephropathy group. GFR is significantly lower in diabetic nephropathy ( $\mathrm{p}$ value $<0.001$ ). UACR, umcp1 and tnf alfa levels are significantly increased in Diabetic nephropathy with $\mathrm{p}$ value $0.006,<0.01,<0.001$ respectively. A recent study has shown TNF alfa stimulates

Table 1. Comparision of anthropometric, clinical and biochemical studies in control, type $2 \mathrm{dm}$, diabetic nephropathy groups.

\begin{tabular}{ccccc}
\hline PARAMETER & CONTROL & Type 2 DM & $\begin{array}{c}\text { Diabetic } \\
\text { Nephropathy }\end{array}$ & $\begin{array}{c}\text { p value measured } \\
\text { by ANOVA }\end{array}$ \\
\hline Age (yrs) & $47.04 \pm 9.1$ & $51.02 \pm 12.12$ & $50.10 \pm 10.92$ & 0.23 \\
BMI (kg/m $\left.{ }^{2}\right)$ & $21.37 \pm 1.72$ & $21.25 \pm 2.32$ & $22.9 \pm 2.59$ & 0.12 \\
SBP (mm of Hg) & $119.04 \pm 4.14$ & $125.12 \pm 12.20$ & $136.84 \pm 17.42$ & 0.002 \\
DBP (mm of Hg) & $70.4 \pm 5.95$ & $75.20 \pm 6.82$ & $74.93 \pm 8.30$ & 0.24 \\
FBG (mg/dl) & $98.44 \pm 5.34$ & $180.84 \pm 64.77$ & $182.24 \pm 59.78$ & 0.008 \\
2 HR PPBG (mg/dl) & $120.02 \pm 9.14$ & $255.04 \pm 75.83$ & $263.52 \pm 70.99$ & $<0.001$ \\
HBA1C (\%) & $4.62 \pm 0.48$ & $7.93 \pm 0.81$ & $8.05 \pm 0.83$ & 0.024 \\
T.chol (mg/dl) & $131.52 \pm 24.8$ & $142.8 \pm 48.99$ & $163.24 \pm 41.25$ & 0.03 \\
TG (mg/dl) & $126.3 \pm 25.7$ & $130.3 \pm 58.04$ & $137.02 \pm 35.11$ & 0.14 \\
HDL (mg/dl) & $58.02 \pm 11.65$ & $61.0 \pm 31.74$ & $59.70 \pm 28.85$ & 0.09 \\
LDL (mg/dl) & $56.84 \pm 20.09$ & $54.92 \pm 25.6$ & $60.14 \pm 21.39$ & 0.32 \\
VLDL (mg/dl) & $30.9 \pm 16.05$ & $28.06 \pm 11.52$ & $25.90 \pm 8.69$ & 0.62 \\
GFR (ml/mnt/1.73 m $\left.{ }^{2}\right)$ & $155.5 \pm 94.91$ & $244.78 \pm 163.38$ & $19.21 \pm 9.51$ & $<0.001$ \\
UACR (mg/g) & $18.46 \pm 12.44$ & $25.21 \pm 3.33$ & $956.97 \pm 761.83$ & 0.006 \\
UMCP1 (ng/l) & $14.88 \pm 11.13$ & $177 \pm 12.23$ & $344.06 \pm 202.31$ & $<0.001$ \\
TNF alfa (ng/l) & $25.03 \pm 14.05$ & $52.02 \pm 10.6$ & $432.76 \pm 92.07$ & $<0.001$ \\
\hline
\end{tabular}


the MCP 1 production via NFKB signalling pathway in rat astrocytes culture [29]. TNF alfa was found to increase $\mathrm{p}^{65}$ and phosphorylated $\mathrm{p}^{65}$ levels in nuclear extracts of rat astrocytes by increasing MCP 1 level. An Indian study p.tilak et al. [22] showed mean level of umcp1 in type $2 \mathrm{dm}$ pts were significantly higher than those control group ( $\mathrm{p}$ value $<0.05$ ) and in between DM,DN umcp1 is significantly higher in microalbuminuria groups than diabetic groups ( $\mathrm{p}$ value $<0.006$ ). In our study we got umcp1 is significantly higher in diabetic nephropathy group ( $\mathrm{p}$ value $<0.01$ ). Wang et al. [30] studied microalbuminuria causes rise in umcp1 level. Gupta S. et al. [31] studied Association of tumor necrosis factor (TNF) promoter polymorphisms with plasma TNF- $\alpha$ levels and susceptibility to diabetic nephropathy in North Indian population and we also reviewed Su. B et al. study which shows UMCP1 is high in diabetic nephropathy as compared to DM with $\mathrm{p}$ value $<0.05$. Monitoring umcp1 is a very good biochemical parameter to know kidney involvement in diabetes.

Table 2 shows NFKB1 gene polymorphism frequencies which are shown. Insertion/insertion polymorphism are $24 \%, 48 \%, 70 \%$ in control, type $2 \mathrm{DM}$, diabetic nephropathy groups respectively. Deletion/deletion polymorphism are $76 \%, 38 \%, 28 \%$ in control, type $2 \mathrm{DM}$, diabetic nephropathy groups. Insertion/deletion polymorphism are $0 \%, 14 \%, 2 \%$ in control, type $2 \mathrm{DM}$, diabetic nephropathy groups (Figure 1). Gautam, A. et al. [21] studied association of biomarkers of inflammation and oxidative stress with the risk of chronic kidney disease in Type 2 diabetes mellitus in North Indian population. Senol Tuncay et al. (2012) studied identification of NFkappaB1 and NF-kappaBI Alpha polymorphisms using PCR-RFLP assay in a Turkish population [25].

Table 3 shows Correlation genotype polymorphism with inflammatory markers have been studied.ins/ins is positively co related with umcp 1 with $r$ factor 0.517 , $\mathrm{p}$ value $<0.01$. This agrees to $\mathrm{S}$. Gupta et al. study. Del/del is positively co related with TNF alfa $\mathrm{r}$ factor equals to $0.43, \mathrm{p}$ value 0.01 . These does not agree with Hilliard B.et al. They had found del/del was not positively correlated with TNF alfa ( $p$ value $<0.05$ ). Ins/del polymorphism is positively co related with NFKB1 gene $\mathrm{r}=0.323$, $\mathrm{p}$ value 0.012 . This holds true for Zhou et al. [32] with $\mathrm{p}$ value $<$ 0.05 and Yang et al. ins allele were associated with increased levels of umcp1 ( $\mathrm{p}$ value $=0.026)$, plasma tnf alfa $(\mathrm{p}=0.030)$ in $\mathrm{DM}, \mathrm{DN}$ groups. Esposito studied hyperglycemia increased the oxidative stress leading to increased inflammatory cytokines like UMCP1,TNF alfa ${ }^{16}$. Among control and diabetes group NFKB1 gene, TNF alfa are not significantly expressed in diabetes group with $\mathrm{p}$ value 0.823 ; $\mathrm{CI}-0.19-0.39$ and $\mathrm{p}$ value 0.062 ; $\mathrm{CI}-54.88-0.91$. In between these umcp1 is significantly expressed in type $2 \mathrm{DM}$ group with $\mathrm{p}$ value $<0.01$; CI -258.29 (-67.74). This finding agrees with Esposito et al. [16] 2002 (p value < 0.05). But these results are not consistent with Gautam et al. In between control and diabetic nephropathy groups all three inflammatory markers NFKB1 gene, umcp1, TNF alfa are significantly increased with $\mathrm{p}$ value 0.001 ; CI $0.14-0.73$, p value $<0.01$; CI $-424.42-(-233.94)$, $\mathrm{p}$ value $<0.01$; CI $-94.93-39.13$ respectively. Our findings are consistent with Shukla R., Kalra S. et al. [31] with p value $<0.005$. 
Table 2. Genotype frequencies of NFKB1 gene polymorphism.

\begin{tabular}{cccc}
\hline genotype & $\begin{array}{c}\text { Control No. } \\
\text { (in percentage) }\end{array}$ & $\begin{array}{c}\text { Type2 DM } \\
\text { No. (in percentage) }\end{array}$ & $\begin{array}{c}\text { Diabetic nephropathy } \\
\text { No. (in percentage) }\end{array}$ \\
\hline Ins/ins & $12(24 \%)$ & $24(48 \%)$ & $35(70 \%)$ \\
del/del & $38(76 \%)$ & $19(38 \%)$ & $14(28 \%)$ \\
Ins/del & $*$ & $7(14 \%)$ & $1(2 \%)$ \\
\hline
\end{tabular}

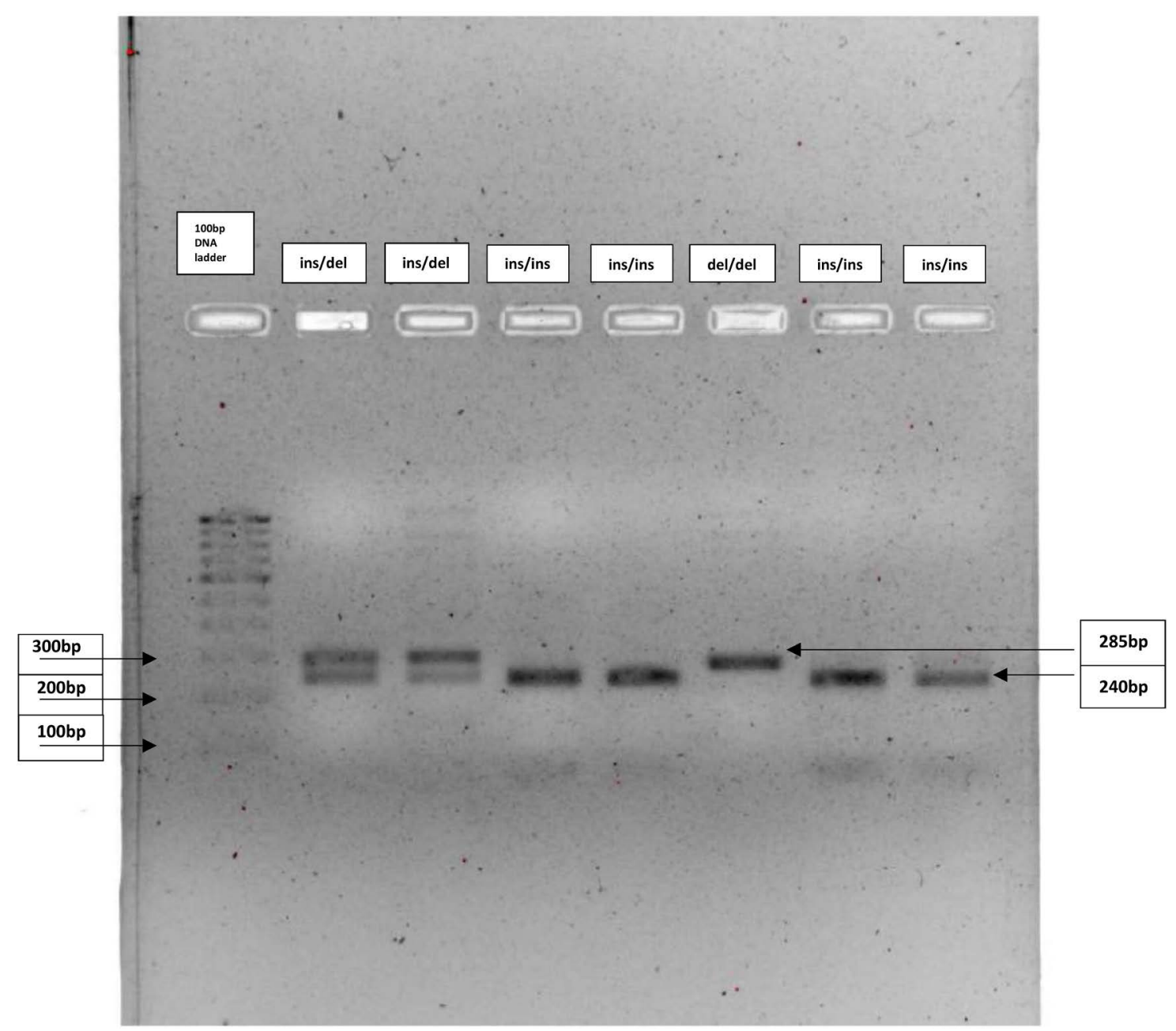

Figure 1. NFkB1 gene polymorphism types on agarose gel picture. Lane 1: 100 bp DNA ladder, Lane 2, 3: ins/del polymorphism, Lane 4, 5, 7, 8: ins/ins polymorphism, Lane 6: del/del polymorphism.

Table 3. Correlation between NFkB1 gene polymorphism types and inflammatory biomarkers.

\begin{tabular}{ccc}
\hline GENOTYPES & UMCP1 & TNF alfa \\
\hline Ins/ins & $\mathrm{r}=0.517$ & $\mathrm{r}=0.172$ \\
& $\mathrm{p}<0.01$ & $\mathrm{p}=0.19$ \\
\hline \multirow{2}{*}{ Del/del } & $\mathrm{r}=0.137$ & $\mathrm{r}=0.43$ \\
& $\mathrm{p}=0.44$ & $\mathrm{p}=0.01$ \\
\hline Ins/del & $\mathrm{r}=0.323$ & $\mathrm{r}=0.34$ \\
& $\mathrm{p}=0.012$ & $\mathrm{p}=0.41$ \\
\hline
\end{tabular}


But our findings differs from a japaneese study may be due to different ethinicity. In between DM and Diabetic nephropathy groups NFKB1 gene, umcp1, TNF alfa are significantly increased with $\mathrm{p}$ value 0.019 ; CI $0.04-0.63$, $\mathrm{p}$ value $<0.01$; CI -261.43 - (-70.96), p value 0.001; CI $-67.94-(-12.15)$ respectively. M. R. Choi et al. found NFKB1 gene polymorphism helps in UMCP1 protein expression. This umcp1 is a major inflammatory marker for development of diabetic nephropathy.

Table 4 shows ins/ins nfkbl gene polymorphism increases the risk of diabetic nephropathy by 2.52 times in diabetes patients. Deletion/deletion nfkb1 gene polymorphism increases the risk of diabetic nephropathy by 0.63 times in diabetes patients. insertion/deletion nfkbl gene polymorphism increases the risk of diabetic nephropathy by 0.12 times in diabetes patients Gautam et al. had found ins/del polymorphism develop 1.90 times nephropathy in diabetes mellitus patients and type $2 \mathrm{DM}$ patients having ins/ins genotype also increased risk of developing nephropathy. In this study -94 ins/ins polymorphism, It is found to increase the risk of developing Diabetic Nephropathy by 2.52 fold in patients with Diabetes $(\mathrm{OR}=2.52,95 \% \mathrm{CI}: 0.04-0.63$, p value $=0.019)($ Table 4$)$. This study results are consistent with O. P. Kalra et al. [33] 2017 with p value $<0.05$. A similar study conducted in sporadic colorectal cancer (CRC), epithelial ovarian cancer (EOC) has supported our findings which suggested ins/ins nfkb1 genotype leads to significantly increased risk of CRC and EOC. Yang X. et al. [19] 2014 have found ins/del polymorphism has significant association with diabetic nephropathy, cancers also. Cause of variation may be our small sample size and geographically different population. Zhou B. et al. [32] studied relationship between NFKB1 -94 insertion/deletion ATTG polymorphism and susceptibility of cervical squamous cell carcinoma risk.

\section{Conclusion}

The results of the current study suggest that the NFKB1 promoter -94 ins/ins polymorphism and ins/del polymorphism are associated with increased possibility of developing nephropathy in patients with diabetes. The results of the current study suggest that the NFKB1 promoter -94 ins/ins polymorphism is associated with increased possibility of developing nephropathy in patients with diabetes. The above results were in consistent with various studies from India and abroad.

Table 4. Association between NFkB1 gene polymorphism and diabetic nephropathy at genotypes level.

\begin{tabular}{cccc}
\hline \multirow{2}{*}{ GENOTYPE } & \multicolumn{3}{c}{ Odds ratio (OR) } \\
\cline { 2 - 4 } & ins/ins & del/del & ins/del \\
\hline Control vs Type 2 DM & 2.9 & 0.19 & $*$ \\
Control vs Diabetic Nephropathy & 7.3 & 0.12 & $*$ \\
Type 2DM vs Diabetic Nephropathy & 2.52 & 0.63 & 0.12 \\
\hline
\end{tabular}


This insertion/insertion NFkB1 gene polymorphism may be considered as a genetic marker for risk of developing nephropathy in patients with T2DM. The limitation of our study is small sample size so, further study should be done with a larger sample size to look for the possibility of ins/ins polymorphism as a potential genetic marker in near future.

\section{Acknowledgements}

Medical Research Unit, SCB Medical College, Cuttack.

\section{Conflicts of Interest}

The authors declare no conflicts of interest regarding the publication of this paper.

\section{References}

[1] IDF (2017) IDF Diabetes Atlas 2017. 8th Edition, Country Report from India. http://diabetesatlas.org/resources/2017-atlas.html

[2] Wolf, G.F., et al. (2007) Cellular \& Molecular Mechanisms of Proteinuria in Diabetic Nephropathy. Nephron Physiology, 106, 26-31. https://doi.org/10.1159/000101797

[3] Behera, S.R., et al. (2017) Morbidity Profile and Causes of Mortality in Type 2 Diabetes Patients: Data from a Tertiary Teaching Hospital from Eastern India. Journal of Diabetes Mellitus, 7, 195-211. https://doi.org/10.4236/jdm.2017.73016

[4] Chawla, R. (2012) Complications of Diabetes. Jaypee Brothers Medical Publishers, New Delhi, 1-53. https://doi.org/10.5005/jp/books/11685

[5] Agarwal, R.P., Ola, V. and Bishnoi, P. (2014) Prevalence of Micro and Macrovascular Complications and Their Risk Factors in Type-2 Diabetes Mellitus. The Journal of the Association of Physicians of India, 62, 504-508.

[6] Pradeepa, R., Prabhu, A.K. and Jebarani, S. (2011) Use of Large Diabetes Electronic Medical Record System in India: Clinical and Research Applications. Journal of Diabetes Science and Technology, 5, 543-552. https://doi.org/10.1177/193229681100500309

[7] Varghese, A., Deepa, R. and Reema, M. (2001) Prevalence of Microalbuminuria in Type-2 Diabetes Mellitus at a Diabetes Centre in South India. Postgraduate Medical Journal, 77, 399-402. https://doi.org/10.1136/pmj.77.908.399

[8] Yajnik, C.S., Naik, S.S. and Rout, K.N. (1992) Urinary Albumin Excretion Ratio (AER) in Newly Diagnosed Type 2 Indian Diabetic Patients Is Associated with Central Obesity and Hyperglycemia. Diabetes Research and Clinical Practice, 17, 55-60. https://doi.org/10.1016/0168-8227(92)90044-R

[9] Diabetes Drafting Group (1985) Prevalence of Small Vessel and Large Vessel Disease in Diabetic Patients from 14-Centres. The World Health Organisation Multinational Study of Vascular Disease in Diabetics. Diabetologia, 28, 615-640. https://doi.org/10.1007/BF00290267

[10] Das, S., Mishra, R.K. and Jena, B.B. (1991) Mortality Events amongst NIDDM Patients in Orissa. Journal of the Association of Physicians of India, 39, 519-520.

[11] Rajapurkar, M.M., John, G.T., Kirpalini, A.L., Abraham, G., Agarwal, S.K., Almeida, A.F., Gang, S., Gupta, A., Modi, G., Pahari, D., Pisharody, R., Prakash, J., Raman, 
A., Rana, D.S., Sharma, R.K., Sahoo, R.N., Sakhuja, V., Tatapudi, R.R. and Jha, V. (2012) What Do We Know about Chronic Kidney Disease in India; First Report of the Indian CKD Registry. BMC Nephrology, 13, 10.

https://doi.org/10.1186/1471-2369-13-10

[12] Das, S., Chandrakanth, M.V., Rout, S.B., Mohanty, R., Singh, S.C., Pattnaik, M. and Sethy, B. (2012) Study of Markers of Atherosclerosis Including Insulin Resistance in Patients with Chronic Renal Failure. Journal of Diabetes Mellitus, 2, 208-213. https://doi.org/10.4236/jdm.2012.22033

[13] Unnikrishnan, R., Rema, M., Pradeepa, R., Deepa, M., Shanthirani, S., Deepa, R. and Mohan, V. (2007) Prevalence and Risk Factors of Diabetic Nephropathy in an Urban South Indian Population, the Chennai Urban Rural Epidemiology Study (CURES 45). Diabetes Care, 30, 2019-2024. https://doi.org/10.2337/dc06-2554

[14] Mani, M.K. (1998) Patterns of Renalp Disease in Indigenous Populations in India. Nephrology, 4, S4-S7. https://doi.org/10.1111/j.1440-1797.1998.tb00461.x

[15] Nayak, S., et al. (2017) Evaluation of Type of Nephropathy in Patients of Type-2 Diabetes Mellitus Department of Medicine, SCB Medical College, Cuttack, India. Journal of Diabetes Mellitus, 7, 281-293. https://doi.org/10.4236/jdm.2017.74023

[16] Esposito, K., Nappo, F., Marfella, R., Giugliano, G., Giugliano, F., Ciotola, M., Quagliaro, L., Ceriello, A. and Giugliano, D. (2002) Inflammatory Cytokine Concentrations Are Acutely Increased by Hyperglycemia in Humans: Role of Oxidative Stress. Circulation, 106, 2067-2072. https://doi.org/10.1161/01.CIR.0000034509.14906.AE

[17] Karin, M. and Ben-Neriah, Y. (2000) Phosphorylation Meets Ubiquitination: The Control of NF-[kappa]B Activity. Annual Review of Immunology, 18, 621-663. https://doi.org/10.1146/annurev.immunol.18.1.621

[18] Barnes, P.J. and Karin, M. (1993) Nuclear Factor-kappaB: A Pivotaltrans-Cription Factor in Chronic Inflammatory Diseases. The New England Journal of Medicine, 36, 1066-1071. https://doi.org/10.1056/NEJM199704103361506

[19] Yang, X., Li, P., Tao, J., Qin, C., Cao, Q., Gu, J., Deng, X., Wang, J., Liu, X., Wang, Z., Wu, B., Gu, M., Lu, Q. and Yin, C. (2014) Association between NFKB1-94ins/del ATTG Promoter Polymorphism and Cancer Susceptibility: An Updated Meta-Analysis. International Journal of Genomics, 2014, Article ID: 612972. https://doi.org/10.1155/2014/612972

[20] Das, S. and Misra, D.P. (2012) Prevalence of Inflammatory Markers (High-Sensitivity C-Reactive Protein, Nuclear Factor-kB, and Adiponectin) in Indian Patients with Type 2 Diabetes Mellitus with and without Macrovascular Complications. Metabolic Syndrome and Related Disorders, 10, 209-213. https://doi.org/10.1089/met.2011.0044

[21] Gautam, A., Gupta, S., et al. (2013) Association of Biomarkers of Inflammation and Oxidative Stress with the Risk of Chronic Kidney Disease in Type 2 Diabetes Mellitus in North Indian Population. Journal of Diabetic Complications, 27, 548-552. https://doi.org/10.1016/j.jdiacomp.2013.07.005

[22] Tilak, P., et al. (2008) MCP-1/CCL2: A New Diagnostic Marker and Therapeutic Target for Progressive Renal Injury in Diabetic Nephropathy. American Journal of Physiology-Renal Physiology, 294, F697-F701. https://doi.org/10.1152/ajprenal.00016.2008

[23] National Kidney Foundation (2012) KDOQI Clinical Practice Guideline for Diabetes and CKD: 2012 Update. American Journal of Kidney Diseases, 60, 850-886. 
[24] World Health Organization (2015) Definition, Diagnosis and Classification of Diabetes Mellitus and Its Complications: Report of a WHO Consultation. Part 1: Diagnosis and Classification of Diabetes Mellitus. World Health Organization, Geneva.

[25] Senol Tuncay, S., Okyay, P. and Bardakci, F. (2010) Identification of NFkappaB1 and NF-kappaBIAlpha Polymorphisms Using PCR-RFLP Assay in a Turkish Population. Biochemical Genetics, 48, 104-112. https://doi.org/10.1007/s10528-009-9302-y

[26] Ziyadeh, G. and Wolf, F.N. (2008) Pathogenesis of the Podocytopathy and Proteinuria in Diabetic Glomerulopathy. Current Diabetes Reviews, 4, 39-45. https://doi.org/10.2174/157339908783502370

[27] Palazhy, S., et al. (2017) Lipid Abnormalities in Diabetic Nephropathy. Diabetes \& Metabolism Journal, 41, 128-134. http://e-dmj.org https://doi.org/10.4093/dmj.2017.41.2.128

[28] Viberti, G. and Wheeldon, N.M. (2002) Microalbuminuria Reduction with Valsartan in Patients with Type 2 Diabetes Mellitus: A Blood Pressure-Independent Effect. Circulation, 106, 672-678. https://doi.org/10.1161/01.CIR.0000024416.33113.0A

[29] Thompson, W.L. and Van Eldik, L.J. (2009) Inflammatory Cytokines Stimulate the Chemokines CCL2/MCP-1 and CCL7/MCP-3 through NFkB and MAPK Dependent Pathways in Rat Astrocytes [Corrected]. Brain Research, 1287, 47-57. https://doi.org/10.1016/j.brainres.2009.06.081

[30] Wang, Y., Chen, J., Chen, L., et al. (1997) Induction of Monocyte Chemoattractant Protein-1 in Proximal Tubule Cells by Urinary Protein. Journal of the American Society of Nephrology, 8, 1537-1545.

[31] Gupta, S., Kalra, S., Mehndiratta, M., Kalra, O.P., Shukla, R. and Gambhir, J.K. (2015) Association of Tumor Necrosis Factor (TNF) Promoter Polymorphisms with Plasma TNF- $\alpha$ Levels and Susceptibility to Diabetic Nephropathy in North Indian Population. Journal of Diabetes and Its Complications, 29, 338-342. https://doi.org/10.1016/j.jdiacomp.2015.01.002

[32] Zhou, B., Qie, M., Wang, Y., Yan, L., Zhang, Z., Liang, A., Wang, T., Wang, X., Song, Y. and Zhang, L. (2010) Relationship between NFKB1-94 Insertion/Deletion ATTG Polymorphism and Susceptibility of Cervical Squamous Cell Carcinoma Risk. Annals of Oncology, 21, 506-511. https://doi.org/10.1093/annonc/mdp507

[33] Kalra, O.P., et al. (2017) Genetic Basis of Diabetic Nephropathy. Annals of the National Academy of Medical Sciences (India), 53, 1-20.

https://doi.org/10.1055/s-0040-1712740 